\title{
Aplicação de indicadores de sustentabilidade para lagoas de estabilização
}

\section{Application of sustainability indicators to stabilization ponds}

\author{
Erich Kellner \\ Doutor em Engenharia Civil, Área de Hidráulica e Saneamento pela Escola de Engenharia de São Carlos da Universidade de São Paulo (EESC/USP). \\ Professor Adjunto da Universidade Federal do ABC (UFABC) \\ Maria do Carmo Calijuri \\ Livre-docente em Engenharia Civil, Área de Hidráulica e Saneamento pela EESC/USP. Professora titular da EESC/USP \\ Eduardo Cleto Pires \\ Livre-docente em Engenharia Civil, Área de Hidráulica e Saneamento pela EESC/USP. Professor titular da EESC/USP
}

\begin{abstract}
Resumo
A escolha de uma alternativa tecnológica para tratamento de efluentes, assim como o local para implantação deve ser precedida de um estudo de sustentabilidade do ambiente. Foi proposto um método para avaliação da sustentabilidade de estações de tratamento de esgoto, baseado nas características ambientais, sociais e econômico-financeiras dessas unidades. O método foi aplicado em três ETE, constituídas por lagoas de estabilização, localizadas nos municípios de Cajati, Jacupiranga e Pariquera-Açu, todas pertencentes à bacia do Baixo Ribeira de Iguape (SP). A falta de dados para alguns parâmetros considerados na composição dos indicadores prejudicou a obtenção de valores mais realistas. O método proposto mostrou-se de fácil visualização da condição de sustentabilidade das ETE constituídas por lagoas de estabilização.
\end{abstract}

Palavras-chave: indicadores de sustentabilidade; lagoas de estabilização; sustentabilidade ambiental.

\section{Abstract}

The choice of an alternative technology for effluent treatment as well as the location for deployment must be preceded by a study of environmental sustainability. A method for assessing the sustainability of wastewater treatment plants, based on environmental, social and economic-financial characteristics was proposed. The method was applied to three wastewater treatment plants using stabilization ponds, located in the municipalities of Cajati, Jacupiranga and Pariquera-Açu, all belonging to the Lower Ribeira de Iguape River basin, in the state of São Paulo, Brazil. The lack of values for some parameters considered in the formulation of indicators undermined the achievement of more realistic values. The proposed method proved to be easy to visualize the condition of sustainability of wastewater treatment stations using stabilization ponds.

Keywords: sustainability indicators; stabilization ponds; environmental sustainability.

\section{Introdução}

O desenvolvimento de indicadores de sustentabilidade tem sido amplamente abordado por pesquisadores e grupos de pesquisa, como IChemE (2001), Fdz-Polanco et al (2005) e Fu-Liu Xu et al (2006).

Segundo Fdz-Polanco et al (2005), um indicador é uma tradução não-quantitativa do princípio da sustentabilidade, cujo objetivo principal é avaliar qualquer condição social, institucional ou ambiental.

O conceito de desenvolvimento sustentável que foi difundido internacionalmente pelo Relatório Brundtland tornou-se a definição mais utilizada na literatura especializada e pode ser entendido, de maneira geral, como o desenvolvimento que contempla as necessidades presentes sem comprometer a capacidade das gerações futuras de suprir suas próprias necessidades.

Segundo Costanza (1994), sustentabilidade é a relação entre sistemas econômicos e sistemas ecológicos maiores, sendo ambos dinâmicos. No entanto, os sistemas ecológicos são caracterizados por mudanças lentas, nos quais a vida humana poderá continuar indefinidamente, proporcionando um desenvolvimento dos indivíduos e das culturas humanas, caso os efeitos das atividades antrópicas sejam compatíveis com a capacidade suporte, não destruindo a diversidade, complexidade e funcionamento dos sistemas ecológicos que dão suporte à vida.

Considerando a sustentabilidade como um conceito dinâmico que engloba um processo de mudança, Sachs (1997) afirma que o conceito de sustentabilidade refere-se a uma nova concepção dos 
limites e do reconhecimento das fragilidades do planeta, ao mesmo tempo em que enfoca a satisfação das necessidades básicas das populações.

Segundo a UNEP (2003), o desenvolvimento sustentável é normalmente dividido em três aspectos fundamentais: ambiental, social e econômico. Se qualquer um desses componentes não for sustentável, o desenvolvimento geral também não será.

No caso de estações de tratamento de esgoto, a aplicação de critérios econômicos como auxiliar na escolha conceptiva é um procedimento aceito universalmente, para o qual existem diferentes métodos, muitos deles desenvolvidos internamente nas empresas de projeto e construção a partir da experiência acumulada na elaboração de orçamentos e acompanhamento de custos construtivos. Esses critérios e procedimentos são amplamente empregados nos estudos de alternativas, obrigatórios no anteprojeto dos sistemas de tratamento de águas residuárias, pois é sobejamente conhecido que, do ponto de vista técnico, em muitos casos, a mesma eficiência no tratamento pode ser conseguida com diferentes configurações.

No entanto, os projetos de saneamento têm extrapolado sua concepção sanitária clássica, assumindo uma abordagem ambiental visando não somente à promoção da saúde humana, mas também à conservação do meio físico e biótico (SOARES, BERNARDES; CORDEIRO NETTO, 2002). Com isso, solidifica-se a preocupação de se incorporarem critérios de sustentabilidade ambiental ao projeto de estações de tratamento de águas residuárias.

Nesse sentido, optou-se pela região do Baixo Ribeira do Iguape, no estado de São Paulo, como cenário para proposição e avaliação de um indicador de sustentabilidade de três estações de tratamento de esgoto concebidas como lagoas de estabilização.

\section{Material e Métodos}

\section{Área de estudos e análise das características dos efluentes finais das estações de tratamento de esgoto avaliadas}

A bacia do rio Ribeira do Iguape situa-se entre as latitudes 2330'e $25^{\circ} 30^{\prime}$ S e longitudes 46 $50^{\prime} \mathrm{e} 50^{\circ} 00^{\prime}$ 'W e abrange uma área de 24.980 $\mathrm{km}^{2}$, dos quais 61\% pertencem ao Estado de São Paulo e 39\% ao Estado do Paraná. Ela apresenta uma conformação alongada no sentido SO-NE, quase paralela à orla marítima, confrontando-se com as bacias dos rios Tietê ao norte, Paranapanema a oeste, Iguaçu ao sul, e tendo a leste pequenos cursos de água da vertente atlântica.

Dentro do sistema do Ribeira de Iguape, foram escolhidas para a realização deste estudo duas microbacias: Jacupiranga e PariqueraAçu, ambas na região do Baixo Ribeira de Iguape. Essa seleção se deve ao fato de os sistemas de tratamento de esgotos sanitários implantados nos municípios serem lagoas de estabilização, bem como ao fato de o lançamento dos efluentes dos sistemas de tratamento ser feito em corpos d'água enquadrados como Classe 2, segundo Decreto Estadual 10.755 (SÃO PAULO, 1977).

$\mathrm{Na}$ análise desenvolvida, foram consideradas as características dos efluentes finais das estações de tratamento de esgoto dos municípios de Cajati, Jacupiranga e Pariquera-Açu, constantes do projeto temático proposto por Calijuri (2003) e dos trabalhos de Hoeppner (2007) e Miwa (2007), e obtidas em três campanhas amostrais, realizadas nos meses de janeiro, abril e julho de 2006.

Para a caracterização das populações das áreas de estudo, empregaram-se os dados fornecidos pelo Serviço Nacional de Informações sobre Saneamento Básico (SNIS) (2007), que trabalha com dados oficiais do Instituto Brasileiro de Geografia e Estatística (IBGE).

\section{ETE Cajati}

Segundo o SNIS (2007), a população total do município era de 33.353 habitantes, sendo que 23.960 habitantes residiam na área urbana, ou seja, o índice de urbanização era de 71,84\%. A população urbana atendida com abastecimento de água potável era de 22.062 habitantes e desses, 15.422 habitantes tinham seus esgotos coletados. Do volume total de esgoto coletado, 89,95\% era encaminhados à ETE, que atendia, consequentemente, uma população de 13.900 habitantes.

A ETE Cajati entrou em operação no ano de 2002, sendo constituída por lagoas de estabilização implantadas segundo o clássico sistema australiano, ou seja, uma lagoa anaeróbia seguida por uma lagoa facultativa, concebida, segundo Miwa (2007) para o tratamento de esgoto com características predominantemente domésticas.

As principais características físicas das lagoas implantadas na ETE Cajati estão contidas na Tabela 1.

\section{ETE Jacupiranga}

Segundo o SNIS (2007), a população total do município era de 18.970 habitantes, e a população urbana era 11.596 habitantes, ou seja, 61,13\% da população total residia na área urbana. Nesse município, o índice de cobertura de atendimento de água potável era de $100 \%$, e 9.568 habitantes eram atendidos por coleta de esgoto, o que representava índice de $82,51 \%$ da população urbana. Do total de esgoto coletado, 89,84\% era encaminhados até a ETE, que equivalia ao atendimento de população da ordem de 8.600 habitantes.

A ETE Jacupiranga entrou em operação no ano de 1998, operando desde então com uma lagoa facultativa aerada seguida por uma lagoa facultativa convencional, tendo como unidade de desinfecção um tanque de cloração. Segundo Hoeppner (2007), a ETE Jacupiranga recebia esgoto com características predominantemente domésticas.

As principais características físicas das lagoas implantadas na ETE Jacupiranga constam na Tabela 2.

\section{ETE Pariquera-Açu}

Segundo dados disponibilizados pelo SNIS (2007), a população total do município correspondia a 20.964 habitantes sendo que desse total 13.924 habitantes $(66,42 \%)$ viviam em áreas urbanas. 
A população atendida com abastecimento de água potável era de 12.647 habitantes, que representava índice de atendimento de $98 \%$. A população atendida com coleta de esgoto equivalia a 10.284 habitantes, ou seja, 73,85\% da população urbana do município, sendo que $100 \%$ do esgoto coletado era encaminhado à ETE.

A ETE Pariquera-Açu entrou em operação no ano de 1998, sendo constituída por tratamento preliminar e dois conjuntos de lagoas, cada um deles segundo o clássico sistema australiano, que compreende uma lagoa anaeróbia seguida de uma lagoa facultativa.

As principais características físicas das lagoas implantadas na ETE Pariquera-Açu constam da Tabela 3.

\section{Indicadores de sustentabilidade}

O indicador de sustentabilidade desenvolvido representa uma adaptação do modelo proposto por Fu-Liu Xu et al (2006), empregando-se alguns dos critérios desenvolvidos pelo IChemE (2001) e modificados para aplicação em lagoas de estabilização.

No conceito de desenvolvimento sustentável, empregado para a construção do indicador de sustentabilidade, foram consideradas três dimensões básicas: ambiental, social e econômico-financeira.

Com relação aos indicadores que exprimem o desenvolvimento ambiental e social, compararam-se os valores das variáveis consideradas a valores-objetivo definidos, a fim de se obterem os melhores resultados nesses campos. O indicador econômico deve refletir a capacidade financeira do empreendimento.

Assim, conhecidos os indicadores de sustentabilidade ambiental, social e econômico, respectivamente ISA, ISS, ISEF, é possível determinar o indicador de sustentabilidade (IS), definido conforme Equação 1.

$I S_{y}=\left(I S A_{y}, I S S_{y}, I S E F_{y}\right)$

Equação 1

Onde:

IS : indicador de sustentabilidade do y-ésimo objeto estudado

\section{Cálculo dos indicadores qualitativos ambiental e social - ISA e ISS}

Os objetivos especificados para se atingir a sustentabilidade ambiental ou social foram agrupados em vetores, ambos de ordem $n$, conforme Equação 2.

$O_{a}=\left[\begin{array}{llll}a_{1} & a_{2} & \ldots & a_{x}\end{array}\right]^{T}$

Equação 2

Onde:

x: número de parâmetros ambientais ou sociais selecionados,

$a_{\mathrm{n}}$ : valor do objetivo especificado para o n-ésimo parâmetro ambiental ou social selecionado.

As matrizes dos indicadores qualitativos ambiental ou social, de ordem $x \times n$, podem ser representadas pela Equação 3 .
Tabela 1 - Dimensões características das lagoas da ETE Cajati

\begin{tabular}{lccc} 
Dimensão característica & Unidade & $\begin{array}{c}\text { Lagoa } \\
\text { anaeróbia }\end{array}$ & $\begin{array}{c}\text { Lagoa } \\
\text { facultativa }\end{array}$ \\
\hline Profundidade & $\mathrm{m}$ & 4 & 1,5 \\
Largura média & $\mathrm{m}$ & 53 & 163 \\
Comprimento médio & $\mathrm{m}$ & 160,5 & 214 \\
Volume & $\mathrm{m}^{3}$ & 25.886 & 50.400
\end{tabular}

Fonte: Adaptado de Miwa (2007)

Tabela 2 - Dimensões características das lagoas da ETE Jacupiranga

\begin{tabular}{lccc} 
Dimensão característica & Unidade & $\begin{array}{c}\text { Facultativa } \\
\text { aerada }\end{array}$ & $\begin{array}{c}\text { Lagoa } \\
\text { facultativa }\end{array}$ \\
Profundidade & $\mathrm{m}$ & 4 & 1,5 \\
Largura média & $\mathrm{m}$ & 40 & 67 \\
Comprimento médio & $\mathrm{m}$ & 40 & 142 \\
Volume & $\mathrm{m}^{3}$ & 6.080 & 12.368 \\
\hline
\end{tabular}

Fonte: Adaptado de Hoeppner (2007).

Tabela 3 - Dimensões características das lagoas da ETE Pariquera-Açú

$\begin{array}{lccc}\text { Dimensão característica } & \text { Unidade } & \begin{array}{c}\text { Lagoas } \\ \text { anaeróbias }\end{array} & \begin{array}{c}\text { Lagoas } \\ \text { facultativas }\end{array} \\ \text { Profundidade } & \mathrm{m} & 3 & 2,25 \\ \text { Largura média } & \mathrm{m} & 38 & 76 \\ \text { Comprimento médio } & \mathrm{m} & 68 & 106 \\ \text { Volume } & \mathrm{m}^{3} & 7.752 & 16.112\end{array}$

Fonte: Adaptado de Hoeppner (2007).

$A_{x, n}=\left[\begin{array}{cccc}d_{1,1} & d_{1,2} & \ldots & d_{1, n} \\ d_{2,1} & d_{2,2} & \ldots & d_{2, n} \\ \vdots & \vdots & \ddots & \vdots \\ d_{x, 1} & d_{x, 2} & \ldots & d_{x, n}\end{array}\right]$

Equação 3

Onde:

$d_{i, j}:$ j-ésimo parâmetro ambiental ou social considerado para o i-ésimo evento.

Com o objetivo de relativizar os elementos que compõem um determinado parâmetro, calcularam-se as matrizes relativizadas ambiental e social conforme Equações 4 e 5 , respectivamente:

$A_{x, n}^{\prime}=\left[\begin{array}{cccc}d_{1,1}^{\prime} & d_{1,2}^{\prime} & \cdots & d_{1, n}^{\prime} \\ d_{2,1}^{\prime} & d_{2,2}^{\prime} & \cdots & d_{2, n}^{\prime} \\ \vdots & \vdots & \ddots & \vdots \\ d_{x, 1}^{\prime} & d_{x, 2}^{\prime} & \cdots & d_{x, n}^{\prime}\end{array}\right]$ onde $d_{i, j}^{\prime}=\left\{\begin{array}{c}0,0 \text { se }\left(\frac{d_{i, j}-a_{j}}{a_{j}}\right)<0,0 \\ \frac{d_{i, j}-a_{j}}{a_{j}} \text { se } 0,0<\left(\frac{d_{i, j}-a_{j}}{a_{j}}\right)<1,0 \\ 1,0 \text { se }\left(\frac{d_{i, j}-a_{j}}{a_{j}}\right) \geq 1,0\end{array}\right.$

Equação 4

$A_{x, n}^{\prime}=\left[\begin{array}{cccc}d_{1,1}^{\prime} & d_{1,2}^{\prime} & \ldots & d_{1, n}^{\prime} \\ d_{2,1}^{\prime} & d_{2,2}^{\prime} & \ldots & d_{2, n}^{\prime} \\ \vdots & \vdots & \ddots & \vdots \\ d_{x, 1}^{\prime} & d_{x, 2}^{\prime} & \ldots & d_{x, n}^{\prime}\end{array}\right]$ onde $d_{i, j}^{\prime}=\left\{\begin{array}{c}1,0 \text { se }\left|\frac{d_{i, j}-a_{j}}{a_{j}}\right| \geq 1,0 \\ \left|\frac{d_{i, j}-a_{j}}{a_{j}}\right| \\ \text { se }\left|\frac{d_{i, j}-a_{j}}{a_{j}}\right|<1,0\end{array}\right.$

Equação 5 
Dessa maneira, os indicadores de sustentabilidade ambiental (ISA) e social (ISS) foram estimados pela Equação 6.

$I S A_{x}$ ou $I S S_{x}=\sum_{j=1}^{n} A_{x, j}^{\prime} \cdot w_{j}$

Equação 6

Onde:

ISA :indicador de sustentabilidade ambiental do x-ésimo evento considerado (adim);

ISS : o indicador de sustentabilidade social do y-ésimo evento considerado (adim);

$A_{x, j}^{\prime}$ : matriz de ordem $x \times n$, formada pelos fatores ambientais ou sociais normalizados.

\section{Determinação dos fatores de ponderação}

A ponderação dos parâmetros que compõem o índice de sustentabilidade é muito significativa, uma vez que procura definir os pesos com que cada parâmetro irá compor tal índice.

Para a atribuição de pesos, adotou-se a técnica proposta por Saaty (1990), como parte de um processo analítico para tomada de decisões, chamado "The analytic hierarchy process".

No método desenvolvido por Saaty (1990), os "n" atributos a serem comparados são dispostos em uma matriz n x n, na mesma ordem tanto nas linhas quanto nas colunas. Desta maneira, o valor de cada termo $\mathrm{q}_{\mathrm{i}, \mathrm{j}}$ é preenchido com um número que representa a importância relativa do atributo da linha $i$ em relação ao atributo j. Consequentemente, tem-se que a matriz [Q] é recíproca, ou seja, $q_{i, j}=1 / q_{j, i}$, aplicada sempre que $\mathrm{j}>\mathrm{i}$. Quando $\mathrm{i}=\mathrm{j}$, tem-se $q_{\mathrm{i}, \mathrm{j}}=1$, e para $\mathrm{i}<\mathrm{j}$, Saaty (1990) propôs uma escala de comparação par a par, dividida em nove níveis numéricos, apresentada na Tabela 4.

Os fatores de ponderação $\left(\mathrm{w}_{\mathrm{i}}\right)$ foram calculados aplicando-se a equação Equação 7 .

$$
w_{i}=\left(\frac{1}{n}\right) \cdot \frac{\sum_{j=1}^{n} q_{i, j}}{\sum_{k=1}^{n} q_{k, j}}
$$

Equação 7

O autovalor máximo $\left(\lambda_{\max }\right)$ do vetor de ponderação $[w]_{n}$ foi calculado pela Equação 8:

$\lambda_{\max }=\frac{1}{n} \cdot\left(\frac{w_{1}^{\prime}}{w_{1}}+\frac{w_{2}^{\prime}}{w_{2}}+\ldots \frac{w_{n}^{\prime}}{w_{n}}\right)$

Onde:

[W']: vetor de ordem n, contendo os elementos ponderados conforme Equação 9.

$\left[W^{\prime}\right]_{n}=[Q]_{n \times n} \times[W]_{n}$

Equação 9

O índice de consistência (CI) do vetor [W'] foi calculado conforme Equação 10.

$C I=\frac{\lambda_{\max }-n}{n-1}$

Equação 10

Onde:

n: ordem do vetor de ponderação [W'].

Saaty (1990) chamou de índice de aleatoriedade (RI) o índice de consistência de uma matriz recíproca gerada aleatoriamente e a partir de simulações usando a escala de 1 a 9 e propôs valores para RI, de acordo com a ordem $n$ da matriz [Q], conforme indicado na Tabela 5.

O grau de consistência (CR) do vetor [W'] foi calculado conforme Equação 11

$C R=\frac{C I}{I R}$

Tabela 4 - Escala de comparação par a par

\begin{tabular}{|c|c|c|}
\hline Grau de importância & Definição & Explicação \\
\hline 1 & Igual importância & Os dois atributos contribuem de forma idêntica para o objetivo \\
\hline 3 & Ligeiramente mais importante & $\begin{array}{l}\text { A análise e a experiência mostram que o atributo i é ligeiramente mais importante } \\
\text { que } o \text { atributo j }\end{array}$ \\
\hline 5 & Significativamente mais importante & $\begin{array}{l}\text { A análise e a experiência mostram que o atributo i é significativamente mais impor- } \\
\text { tante que o atributo j; }\end{array}$ \\
\hline 7 & Fortemente mais importante & $\begin{array}{l}\text { A maior importância do atributo i em relação ao atributo j pode ser demonstrada na } \\
\text { prática; }\end{array}$ \\
\hline 9 & Extremamente mais importante & $\begin{array}{l}\text { Sem qualquer dúvida o atributo i é absolutamente predominante para o objetivo em } \\
\text { relação ao atributo j; }\end{array}$ \\
\hline $2,4,6,8$ & Valores intermediários & Podem ser utilizados quando necessário, a critério do julgador; \\
\hline $1 / 3$ & Ligeiramente menos importante & $\begin{array}{l}\text { A análise e a experiência mostram que o atributo i é ligeiramente menos importante } \\
\text { que o atributo j; }\end{array}$ \\
\hline $1 / 5$ & Significativamente menos importante & $\begin{array}{l}\text { A análise e a experiência mostram que o atributo i é significativamente menos } \\
\text { importante que o atributo j; }\end{array}$ \\
\hline $1 / 7$ & Fortemente menos importante & $\begin{array}{l}\text { A menor importância do atributo i em relação ao atributo j pode ser demonstrada na } \\
\text { prática; }\end{array}$ \\
\hline $1 / 9$ & Extremamente menos importante & Sem qualquer dúvida o atributo i é absolutamente sem importância para o atributo j. \\
\hline
\end{tabular}

Fonte: Saaty (1990). 
Para a composição do indicador de sustentabilidade ambiental (ISA), foram considerados nove fatores de ponderação característicos para determinação da qualidade do efluente final das lagoas de estabilização: demanda bioquímica de oxigênio (DBO), oxigênio dissolvido (OD), coliformes fecais, $\mathrm{pH}, \mathrm{N}$-amoniacal, fósforo total, clorofila-a, gás metano eliminado para a atmosfera $\left(\mathrm{CH}_{4}\right)$ e gás sulfídrico eliminado para a atmosfera $\left(\mathrm{H}_{2} \mathrm{~S}\right)$. Os sete primeiros parâmetros escolhidos referem-se especificamente à qualidade do efluente final, medidos conforme metodologia proposta por APHA (1999), já os dois últimos parâmetros adotados referem-se, respectivamente, à produção de gás metano contribuinte ao efeito estufa e à acidificação atmosférica, estimados conforme Cetesb (2006) e Silva (2007), respectivamente. Com exceção do parâmetro $\mathrm{OD}$, todos os demais parâmetros que compõem o ISA possuem a característica de, quanto maior o valor do parâmetro em relação ao objetivo fixado, pior será a qualidade do efluente. Assim, o fator de ponderação do parâmetro oxigênio dissolvido foi multiplicado por (-1), de maneira a representar essa característica em relação aos demais fatores de ponderação.

Para a composição do indicador de sustentabilidade social (ISS), foram considerados seis fatores: tarifa média praticada, despesa média por funcionário, número de reuniões com organizações externas, número de acidentes de trabalho, número de autuações do órgão ambiental, porcentagem da população atendida.

\section{Determinação dos objetivos sustentáveis}

Os objetivos considerados sustentáveis para os indicadores ambiental e social foram estabelecidos, em sua maioria, a partir de valores verificados na literatura.

Para a determinação das metas ambientais para os fatores $\mathrm{DBO}$, OD, coliformes fecais, pH, N-amoniacal, fósforo total e clorofila-a, foram estabelecidos os valores constantes na Resolução CONAMA 357/2005 (BRASIL, 2005) considerando-se um corpo d'água enquadrado como Classe 2.

Para a determinação da meta para a massa de gás metano eliminado para a atmosfera, considerou-se a mesma taxa de eliminação para atmosfera estimada pela Cetesb (2006) para o ano de 1996, mantendo-se assim os preceitos da sustentabilidade a partir das considerações estabelecidas no protocolo de Kyoto.

Considerando os efeitos do gás sulfídrico na atmosfera, como a acidificação das chuvas, neste trabalho propõe-se que a emissão desse gás seja zero, ou seja, meta nula.

Com relação à meta estipulada para a tarifa média de água e esgoto praticada pelas prestadoras de serviço de água e esgoto, considerou-se a média do indicador 1004 estabelecido pelo SNIS (2007) para o Estado de São Paulo.

A meta fixada para o fator social 'Despesa média anual por funcionário' tomou como parâmetro a média aritmética para o Estado de São Paulo do indicador 1008 estabelecido pelo SNIS (2007).
O fator social 'Número de reuniões com organizações externas' considera a relação formal mantida com organismos da sociedade civil organizada (ONGs, órgãos ambientais, entidades de classe, etc). Dessa maneira, considerou-se como meta o número de 12 reuniões formais por ano.

Com relação ao 'Número de acidentes de trabalho' na ETE, bem como o 'Número de autuações pelo órgão ambiental', embora seja desejável que não haja tais episódios, estimou-se como aceitável a ocorrência de um evento por ano para cada um desses fatores sociais.

Em decorrência da necessidade da universalização dos serviços de saneamento básico, estabelecido pela lei número 11.445, de 5 de janeiro de 2007, fixou-se como meta o atendimento a $100 \%$ da população.

\section{Cálculo do indicador quantitativo econômico- financeiro (ISEF)}

O custo total (CT) contempla, basicamente, os custos de aquisição de área, licenciamento, construção, depreciação, amortização, manutenção e operação, estando incluídos os custos com pessoal, energia elétrica, produtos químicos e remoção e disposição de lodo, todos trazidos a valor presente, considerando-se uma taxa de juros de $12 \%$ ao ano.

Obtido o custo final da ETE, considerou-se um percentual (f) da receita operacional direta de esgoto, destinado unicamente à ETE em análise, aplicado à relação entre a população atendida pela ETE e a população total atendida por esgotamento sanitário e, portanto, passível de pagamento de tarifação.

A receita operacional direta de esgoto é um dado disponibilizado pelo Sistema Nacional de Informação sobre Saneamento (SNIS), referenciado como F03, relativo ao valor faturado anualmente em decorrência da prestação do serviço de esgotamento sanitário e resultante exclusivamente da aplicação de tarifas.

Para efeito de cálculo, considerou-se que 50\% do valor arrecadado com as tarifas são aplicados na ETE.

A relação entre o custo final da ETE e o montante anual de recursos alocados a ela resulta no tempo necessário para o custeio da instalação, o qual deve ser menor ou igual ao horizonte de projeto (HP).

Dessa maneira, o índice de sustentabilidade econômico-financeira (ISEF) foi calculado pela Equação 12 .

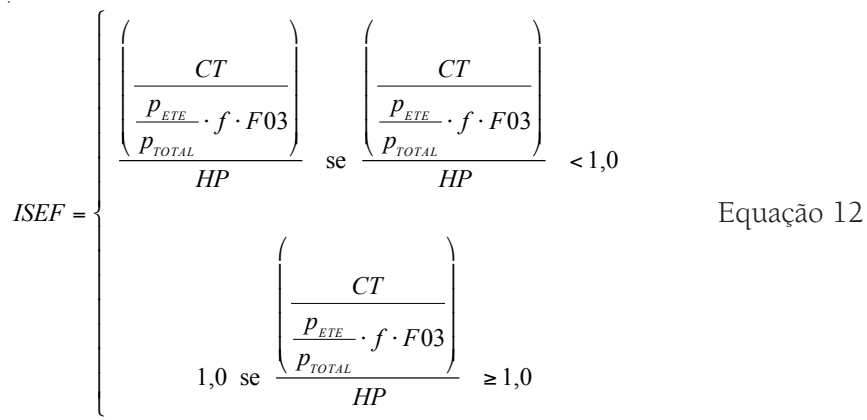




\section{RESULTADOS}

\section{Determinação dos objetivos de sustentabilidade e dos fatores de ponderação}

\section{Para a construção do ISA}

Analisando par a par a importância dos fatores considerados com base no critério proposto por Saaty (1991), construíram-se as matrizes Q, W e W', conforme mostrado nas Equações 13, 14 e 15, respectivamente.

$Q=\left[\begin{array}{ccccccccc}1 & 1 & 1 & 1 & 1 & 3 & 3 & 3 & 3 \\ 1 & 1 & 1 & 1 & 1 & 3 & 3 & 3 & 3 \\ 1 & 1 & 1 & 1 / 3 & 1 / 3 & 3 & 3 & 3 & 3 \\ 1 & 1 & 3 & 1 & 1 & 1 & 3 & 3 & 3 \\ 1 & 1 & 3 & 1 & 1 & 3 & 3 & 3 & 3 \\ 1 / 3 & 1 / 3 & 1 / 3 & 1 & 1 / 3 & 1 & 3 & 3 & 3 \\ 1 / 3 & 1 / 3 & 1 / 3 & 1 / 3 & 1 / 3 & 1 / 3 & 1 & 3 & 3 \\ 1 / 3 & 1 / 3 & 1 / 3 & 1 / 3 & 1 / 3 & 1 / 3 & 1 / 3 & 1 & 3 \\ 1 / 3 & 1 / 3 & 1 / 3 & 1 / 3 & 1 / 3 & 1 / 3 & 1 / 3 & 1 / 3 & 1\end{array}\right]$

Equação 13

$W=\left[\begin{array}{lllllllll}1,489 & 1,489 & 1,270 & 1,556 & 1,740 & 0,906 & 0,612 & 0,469 & 0,359\end{array}\right]^{T}$

Equação 14

$W^{\prime}=Q \cdot W=\left[\begin{array}{lllllllll}0,150 & 0,150 & 0,126 & 0,157 & 0,172 & 0,092 & 0,064 & 0,050 & 0,038\end{array}\right]^{T}$

Equação 15

O autovalor da matriz $\mathrm{W}$ resultou em $\lambda=9,784$ e o grau de consistência das importâncias atribuídas na matriz Q resultou em $\mathrm{CR}=0,068$.

\section{Para a construção do ISS}

Analogamente, para ISS, analisou-se par a par a importância dos fatores considerados, segundo o critério proposto por Saaty (1991), chegando-se às matrizes $\mathrm{Q}, \mathrm{W}$ e W', conforme mostrado, respectivamente, nas Equações 16, 17 e 18

$$
Q=\left[\begin{array}{cccccc}
1 & 1 & 4 & 4 & 4 & 7 \\
1 & 1 & 4 & 4 & 4 & 7 \\
1 / 4 & 1 / 4 & 1 & 3 & 3 & 3 \\
1 / 4 & 1 / 4 & 1 / 3 & 1 & 3 & 3 \\
1 / 4 & 1 / 4 & 1 / 3 & 1 / 3 & 1 & 3 \\
1 / 7 & 1 / 7 & 1 / 3 & 1 / 3 & 1 / 3 & 1
\end{array}\right]
$$

Tabela 5 - Índice de aleatoriedade (RI)

\begin{tabular}{cccccc|}
$\mathbf{n}$ & $\mathbf{R I}$ & $\mathbf{n}$ & $\mathrm{RI}$ & $\mathrm{n}$ & $\mathrm{RI}$ \\
\hline 1 & 0 & 6 & 1,24 & 11 & 1,51 \\
\hline 2 & 0 & 7 & 1,32 & 12 & 1,48 \\
3 & 0,58 & 8 & 1,41 & 13 & 1,56 \\
\hline 4 & 0,9 & 9 & 1,45 & 14 & 1,57 \\
\hline 5 & 1,12 & 10 & 1,49 & 15 & 1,59 \\
\hline
\end{tabular}

Fonte: Saaty (1990).
$W=\left[\begin{array}{llllll}2,074 & 2,074 & 0,926 & 0,695 & 0,465 & 0,235\end{array}\right]^{T} \quad$ Equação 17

$W^{\prime}=Q \cdot W=\left[\begin{array}{llllll}0,327 & 0,327 & 0,138 & 0,101 & 0,070 & 0,030\end{array}\right]^{T} \quad$ Equação 18

$\mathrm{O}$ autovalor da matriz $\mathrm{W}$ resultou em $\lambda=6,538$, e o grau de consistência das importâncias atribuídas na matriz $Q$ resultou em $\mathrm{CR}=0,087$.

Os fatores de ponderação e os objetivos estabelecidos para se buscar a sustentabilidade ambiental e social estão reunidos na Tabela 6 .

\section{Estimativa dos indicadores de sustentabilidade}

Segundo Miwa (2007) e Hoeppner (2007), para cada uma das três campanhas realizadas (janeiro, abril e julho), a caracterização dos efluentes de cada uma das ETE foi feita com amostras compostas a partir da coleta de cinco amostras simples, coletadas, para ambos os casos, às 8h, 14h, 20h, $2 \mathrm{~h}$ e $8 \mathrm{~h}$, compondo o ciclo nictemeral.

Os resultados obtidos das caracterizações dos efluentes das ETE de Cajati, Jacupiranga e Pariquera-Açu estão apresentados na Tabela 7.

As Tabelas 8 e 9 apresentam os valores médios característicos dos Sistemas de Tratamento de Esgoto dos municípios de Cajati, Jacupiranga e Pariquera-Açu empregados no cálculo do ISS e do ISEF, respectivamente.

A partir dos dados apresentados nas Tabelas 7, 8 e 9 relacionados com os objetivos estipulados para cada variável e apresentados na Tabela 6, calcularam-se os indicadores de sustentabilidade ambiental, social e econômico-financeiro para cada uma das ETE analisadas, estando os resultados apresentados na Tabela 10 e em forma de gráficos na Figura 1

\section{Discussão}

O uso de indicadores, além de ser uma ferramenta da gestão ambiental, é essencial para informar a sociedade sobre o quão distante se está da sustentabilidade, permitindo que esses indicadores sejam retroalimentados sistematicamente.

$\mathrm{Na}$ aplicação do conceito de sustentabilidade, foram consideradas três dimensões básicas: ambiental, social e econômico-financeira, como possibilidades apresentadas por UNEP (2003).

Nesse sentido, foi proposto o modelo gráfico triangular, cujos vértices são formados pelos indicadores de sustentabilidade ambiental (ISA), social (ISS) e econômico-financeiro (ISEF), aplicado a três estações de tratamento de esgoto localizadas na região do Baixo Ribeira de Iguape (SP).

Cada uma das três dimensões básicas consideradas foi convertida em indicadores de sustentabilidade que variam de zero a um. Esses indicadores foram dispostos graficamente em três eixos concorrentes entre si, caracterizando a tríade da sustentabilidade que 
Tabela 6 - Fatores de ponderação e objetivos estabelecidas para o cálculo dos indicadores de sustentabilidade ambiental e social

\begin{tabular}{|c|c|c|c|c|}
\hline Índice & Parâmetros & Unidade & Objetivo & W' (adim.) \\
\hline \multirow[t]{9}{*}{ Ambiental } & DBO & $\mathrm{mg} / \mathrm{L}$ & 60 & 0,15 \\
\hline & OD & $\mathrm{mg} / \mathrm{L}$ & 5 & $-0,15$ \\
\hline & Coliformes fecais & NMP & $10^{3}$ & 0,13 \\
\hline & $\mathrm{pH}$ & - & 7 & 0,16 \\
\hline & N-amoniacal & $\mathrm{mg} / \mathrm{L}$ & 20 & 0,17 \\
\hline & Fósforo total & $\mathrm{mg} / \mathrm{L}$ & 2 & 0,09 \\
\hline & $\mathrm{CH}_{4}$ emitido para atmosfera & $\mathrm{kgCH}_{4} /$ hab.ano & 0,365 & 0,06 \\
\hline & $\mathrm{H}_{2} \mathrm{~S}$ gasoso emitido para atmosfera & $\mathrm{kgH}_{2} \mathrm{~S} / \mathrm{hab}$.ano & 0 & 0,05 \\
\hline & Clorofila-a & $\mu \mathrm{g} / \mathrm{L}$ & 30 & 0,04 \\
\hline \multirow[t]{6}{*}{ Social } & Tarifa média praticada & $\mathrm{R} \$ / \mathrm{m}^{3}$ & 1,35 & 0,33 \\
\hline & Despesa média anual por funcionário & $\mathrm{R} \$ /$ func. & $81.022,75$ & 0,33 \\
\hline & Número de reuniões com organizações externas & Número de ocorrências/ano & 12 & 0,14 \\
\hline & Número de acidentes de trabalho & Número de ocorrências/ano & 1 & 0,10 \\
\hline & Número de autuações do órgão ambiental & Número de ocorrências/ano & 1 & 0,07 \\
\hline & População urbana atendida & $\%$ & 100 & 0,03 \\
\hline
\end{tabular}

Fonte: Adaptado de SNIS (2007), Brasil (2007), Cetesb (2006), Brasil (2005), IChemE (2001), São Paulo (1977).

Tabela 7 - Características dos efluentes das Estações de Tratamento de Esgoto Cajati, Jacupiranga e Pariquera-Açu nas três campanhas realizadas

\begin{tabular}{|c|c|c|c|c|c|c|c|c|c|}
\hline \multirow[t]{2}{*}{ Parâmetros } & \multicolumn{3}{|c|}{ ETE Cajati } & \multicolumn{3}{|c|}{ ETE Jacupiranga ${ }^{(a)}$} & \multicolumn{3}{|c|}{ ETE Pariquera-Açu(a) } \\
\hline & Jan/06 & Abr/06 & Jul/06 & Jan/06 & $\mathrm{Abr} / 06$ & Jul/06 & Jan/06 & $\mathrm{Abr} / 06$ & $\mathrm{Jul} / 06$ \\
\hline Vazão (L/s) & 38,0 & 38,0 & 38,0 & 7,2 & 7,2 & 2,6 & 12,0 & 11,9 & 14,5 \\
\hline $\mathrm{OD}$ (mg/L) & 2,6 & 2,2 & 4,0 & 8,1 & 17,6 & 10,4 & 4,0 & 9,6 & 5,0 \\
\hline $\mathrm{pH}$ & 9,3 & 8,0 & 9,5 & 9,0 & 7,5 & 8,2 & 7,6 & 8,5 & 7,5 \\
\hline Fósforo total (mg/L) & 1,8 & 1,8 & 3,1 & 2,5 & 2,0 & 3,0 & 2,0 & 1,8 & 4,2 \\
\hline NTK (mg/L) & 14,3 & 8,5 & 9,8 & 18,0 & 16,0 & 33,0 & 15,0 & 13,0 & 30,0 \\
\hline $\mathrm{N}-\mathrm{NH}_{3}(\mathrm{mg} / \mathrm{L})$ & 5,1 & 3,3 & 0,5 & 13,0 & 10,0 & 25,0 & 10,0 & 10,0 & 22,0 \\
\hline Clorofila-a ( $\mu \mathrm{g} / \mathrm{L})$ & $4,2.10^{3}$ & $3,5.10^{3}$ & $3,5.10^{3}$ & $0,6.10^{3}$ & $0,4.10^{3}$ & $0,6.10^{3}$ & $0,7.10^{3}$ & $0,6.10^{3}$ & $0,2.10^{3}$ \\
\hline CF (NMP/100 mL) & $1,7.10^{3}$ & $2,4.10^{3}$ & $0,2.10^{3}$ & - & - & - & - & - & - \\
\hline DBO (mg/L) & 45 & 19 & 11 & (25) & (15) & (13) & (30) & (13) & (13) \\
\hline DQO (mg/L) & 209 & 125 & 186 & 100 & 60 & 50 & 120 & 50 & 50 \\
\hline
\end{tabular}

Fonte: adaptado de Miwa (2007) e Hoeppner (2007).

(a) Para os efluentes das ETE, os valores da DBO, grafados entre parênteses, foram estimados empregando-se a relação DQO/DBO = 4, a partir dos resultados obtidos por Hoeppner (2007) para DQO.

Tabela 8 - Valores médios característicos dos Sistemas de Tratamento de Esgoto dos municípios de Cajati, Jacupiranga e Pariquera-Açú empregados no cálculo do ISS

\begin{tabular}{lcccc}
\hline Parâmetros & Unidade & ETE Cajiti & ETE Jacupiranga & ETE Pariquera-Açú \\
Tarifa média praticada para água e esgoto & $\mathrm{R} \$ \mathrm{~m}^{3}$ & 1,52 & 1,63 & 1,7 \\
Despesa média anual por funcionário & $\mathrm{R} \$$ /funcionário & $67.246,93$ & $74.501,64$ & $67.297,52$ \\
Número de reuniões com organizações externas & Número de ocorrências/ano & 12 & 12 & 12 \\
Número de acidentes de trabalho & Número de ocorrências/ano & 0 & 0 & 0 \\
Número de autuações do órgão ambiental & Número de ocorrências/ano & 0 & 0 & 0 \\
População urbana atendida & $\%$ & 57,89 & 74,13 & 73,85 \\
\hline
\end{tabular}

Fonte: adaptado de SNIS (2007).

Tabela 9 - Valores médios característicos dos Sistemas de Tratamento de Esgoto dos municípios de Cajati, Jacupiranga e Pariquera-Açu empregados no cálculo do ISEF

\begin{tabular}{lcccc} 
Parâmetros & Unidade & ETE Cajati & ETE Jacupiranga & ETE Pariquera-açú \\
Horizonte de projeto & Anos & 20 & 20 & 20 \\
Vazão de projeto & $\mathrm{L} / \mathrm{s}$ & 54,2 & 33,5 & 23,8 \\
Custo de Implantação(a) & $\mathrm{R} \$$ & $3.600 .000,00$ & $2.340 .000,00$ & $1.425 .000,00$ \\
Custo de operação/manutenção(a) & $\mathrm{R} \$ /$ ano & $192.000,00$ & $438.700,00$ & $76.000,00$ \\
Custo total trazido a valor presente & $\mathrm{R} \$$ & $5.034 .133,18$ & $5.616 .844,92$ & $1.992 .677,72$ \\
Receita operacional direta de esgoto & $\mathrm{R} \$ /$ ano & $1.223 .654,04$ & $909.881,38$ & $1.112 .447,91$ \\
\hline
\end{tabular}

Fonte: adaptado de SNIS (2007), Miwa (2007), Hoeppner (2007).

(a) Os valores empregados nos custos de implantação, operação e manutenção foram obtidos a partir de observações feitas pelos autores corroborados pelos intervalos citados por von Sperling (2005). 
Tabela 10 - Indicadores de sustentabilidade ambiental, social e econômico-financeiro para as ETE Cajati, Jacupiranga e Pariquera-Açu

\begin{tabular}{lccccccccc} 
Indicador & \multicolumn{3}{c}{ ETE Cajati } & \multicolumn{3}{c}{ ETE Jacupiranga } & \multicolumn{3}{c}{ ETE Pariquera-Açu } \\
\cline { 2 - 11 } & Jan/06 & Apr/06 & Jul/06 & Jan/06 & Apr/06 & Jul/06 & Jan/06 & Apr/06 & Jul/06 \\
ISA & 0,25 & 0,258 & 0,211 & 0,074 & 0 & 0,063 & 0,117 & 0 & 0,225 \\
ISS & 0,28 & 0,28 & 0,28 & 0,273 & 0,273 & 0,273 & 0,324 & 0,324 & 0,324 \\
ISEF & 0,711 & 0,711 & 0,711 & 0,833 & 0,833 & 0,833 & 0,309 & 0,309 & 0,309 \\
\hline
\end{tabular}

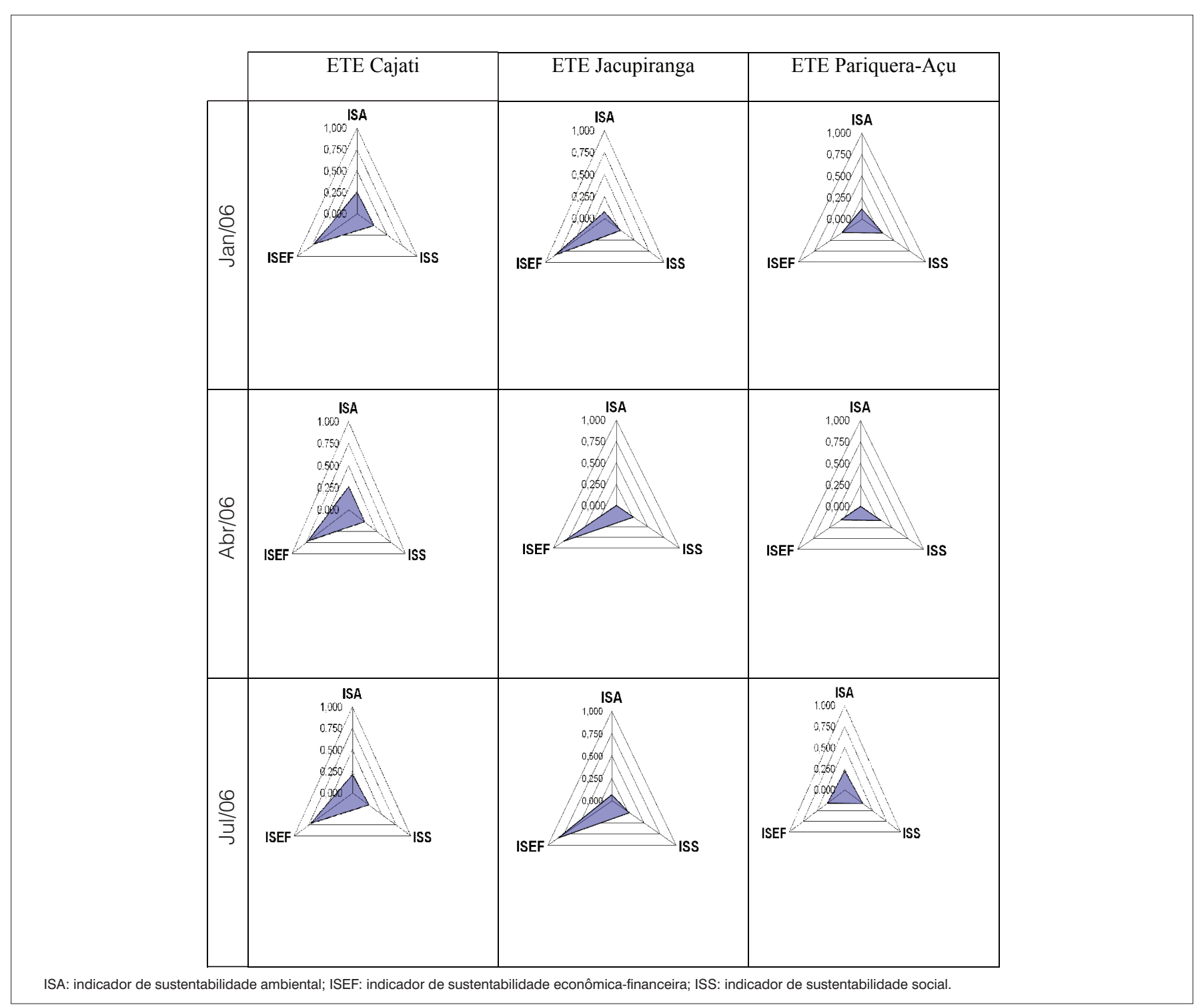

Figura 1 - Triângulos de sustentabilidade obtidos para as campanhas realizadas nas ETE Cajati, Jacupiranga e Pariquera-Açu

permite a visualização de que quanto mais próximo de zero um determinado índice se situar, mais próximo da condição de sustentabilidade estará.

No entanto, como a sustentabilidade não pode ser medida segundo um único índice, quanto menor e mais centrada for a área triangular formada pelos vértices ISA, ISS e ISEF, maior será a condição de sustentabilidade observada. Assim, quanto maior for a distância entre a origem do gráfico e um dos vértices considerados, mais distante esse indicador estará da condição de sustentabilidade proposta.
Os objetivos sustentáveis para os eixos ambiental, social e econômico-financeiro foram definidos, em sua maioria, a partir de limites impostos pela Resolução CONAMA n. 357/2005 e por informações disponibilizadas pelo SNIS (2007).

Os valores dos parâmetros obtidos para cada uma das três ETEs analisadas, apresentados nas Tabelas 7, 8 e 9, foram relativizados a partir dos valores objetivos, característicos do cenário sustentável, apresentados na Tabela 6, e ponderados par a par segundo o grau de importância considerado. 
Segundo Saaty (1990), a matriz de composição paritária é considerada aceitável se o grau de consistência for inferior a 0,10.

O vetor ponderado empregado na composição do ISA, representado pela Equação 15, resultou em grau de consistência de 0,068; já para o vetor ponderado do ISS, representado pela Equação 18, resultou em grau de consistência de 0,087.

Para o ISEF não se aplicou a ponderação dos parâmetros considerados, pois os mesmos não precisaram ser hierarquizados, bastando, neste caso, a simples verificação da capacidade de pagamento dos custos de implantação, construção operação e manutenção ao longo do horizonte de projeto face às tarifas cobradas pelo operador do sistema.

Para cada uma das três ETE consideradas, observou-se a variação dos indicadores de sustentabilidade para três épocas do ano.

Devido à ausência dos valores para coliformes fecais, os ISA das ETE Jacupiranga e Pariquera-Açu ficaram comprometidos, sendo considerados, para efeito de cálculo, nulos. A relativização desse parâmetro com o objetivo definido conduz a um indicador que pode assumir o valor zero ou um, conforme explicitado na Equação 4. Assim, se aplicados os fatores de ponderação, os ISA para as ETE Jacupiranga e Pariquera-Açu, seus valores tornar-se-iam 0,126.

Os dados característicos tanto do esgoto bruto quanto do efluente da ETE Cajati para o período de julho/2006 devem ser observados com cautela. Segundo Miwa (2007), o esgoto bruto apresentou-se muito diluído em relação aos padrões normalmente observados para esgotos sanitários e as amostragens do período foram feitas logo após um período de interrupção na sua operação, o que poderia explicar a baixa concentração de $\mathrm{N}_{-} \mathrm{NH}_{3}$. Além disso, a pesquisadora encontrou relação DQO/DBO para o esgoto bruto da ordem de 24 para esse mesmo período, dando um forte indício da contribuição de efluente industrial. Segundo von Sperling (2005), a relação DQO/DBO para esgoto bruto sanitário varia de 1,3 a 2,4.

A falta de dados sobre a concentração de sulfatos nas unidades de tratamento impossibilitou a estimativa da concentração de sulfetos, conforme proposto por Silva (2007).

De maneira semelhante ao exposto anteriormente, na ausência desse parâmetro, foi considerado, para efeito de cálculo, valor nulo. Assim, ocorrendo valores superiores para a concentração de sulfetos, os valores do ISA para as ETE consideradas poderiam aumentar de 0,050

A ausência dos valores para alguns dos parâmetros necessários para composição do ISA, bem como para a análise global dos indicadores de sustentabilidade para as ETE consideradas, impossibilita uma discussão mais aprofundada sobre o desempenho da cada uma das unidades de tratamento sob a ótica da sustentabilidade, em especial sob a dimensão ambiental.

Da análise dos resultados apresentados na Tabela 10 e na Figura 1, é possível perceber que o ISS e o ISEF das ETE consideradas não variaram ao longo dos períodos analisados, uma vez que os parâmetros que compõem esses indicadores variam anualmente.
Para o ISS, as três ETE apresentaram valores muito próximos entre si, sendo 0,280; 0,273 e 0,324 para as unidades de Cajati, Jacupiranga e Pariquera-Açu, respectivamente.

Para o ISEF, as ETE de Cajati e Jacupiranga apresentaram valores da mesma ordem de grandeza, resultando 0,711 e 0,833, respectivamente, o que indica uma maior proximidade da capacidade suporte. Por outro lado, a ETE Pariquera-Açu apresentou ISEF de 0,309, valor mais próximo da condição de equilíbrio, muito provavelmente devido ao menor custo anual com operação e manutenção dessa unidade de tratamento em comparação às outras duas ETE.

Vale ressaltar que alguns dos parâmetros considerados no ISEF, como os custos de implantação, operação e manutenção, foram adotados com base na literatura, podendo não exprimir a condição real das ETE consideradas.

Ainda que se considerem as devidas cautelas já mencionadas e devido à ausência de alguns parâmetros que constituem o ISA, na Figura 1 é possível observar que a ETE Pariquera-Açu foi aquela que se mostrou mais próxima à condição de sustentabilidade proposta, apresentando um triângulo mais regular e centrado na origem, indicando com isso um maior equilíbrio entre as dimensões de sustentabilidade consideradas, já que não houve uma tendência por uma das dimensões consideradas, além de as áreas serem, visualmente, menores do que as demais, indicando uma situação mais próxima da condição de sustentabilidade proposta.

\section{Conclusão}

Com base nos resultados obtidos neste trabalho, concluiu-se que:

- as matrizes de composição paritária empregadas na priorização dos parâmetros considerados na composição dos indicadores de sustentabilidade ambiental e social foram aceitáveis, já que os graus de consistência obtidos foram inferiores a 0,10;

- o método proposto para análise da sustentabilidade das três ETE consideradas apresentou simplicidade nos cálculos e na representação gráfica, além de flexibilidade na determinação dos cenários característicos da sustentabilidade;

- os resultados apresentados devem ser considerados com cautela devido principalmente à ausência de alguns valores que compõem o ISA, bem como a adoção de valores que constam na bibliografia mas não observados de fato.

\section{Agradecimentos}

Os autores agradecem ao Conselho Nacional de Desenvolvimento Científico e Tecnológico (CNPq) pelas bolsas concedidas, à Doutora Adriana Poli Miwa e Msc. Ana Hoeppner, e à Companhia de Saneamento Básico do Estado de São Paulo (Sabesp) pelos dados fornecidos. 


\section{Referências}

APHA/AWWA/WEF. Standard methods for examination of water and wastewater. 19 $9^{\text {th }}$ ed. Washington: APHA, 1999.

BRASIL. Ministério do Meio Ambiente. Dispõe sobre a classificação dos corpos de água e diretrizes ambientais para o seu enquadramento, bem como estabelece as condições e padrões de lançamento de efluentes, e dá outras providências. Resolução CONAMA n. 357, de 17 de março de 2005. Brasília, DF, 2005. p. 23.

Ministério do Meio Ambiente. Estabelece diretrizes nacionais para o saneamento básico; e dá outras providências. Lei n. 11.445, de 15 de Janeiro de 2007, Brasília, DF, 2007.

CALIJURI, M.C. (Coord.). Estudo dos sistemas naturais e artificiais redutores de cargas poluidoras para a sustentabilidade dos recursos hídricos do Baixo Ribeira de Iguape SP. Projeto temático. Escola de Engenharia de São Carlos. Universidade de São Paulo. Processo Fapesp n. 02/13449-1, 2003.

COMPANHIA DE TECNOLOGIA DE SANEAMENTO AMBIENTAL (CETESB). Primeiro inventário brasileiro de emissões antrópicas de gases de efeito estufa: relatório de referência. Emissões de metano no tratamento e na disposição de resíduos. Brasil: Ministério da Ciência e Tecnologia, 2006.

CONSTANZA, R. Economia ecológica: uma agenda de pesquisa. In: MAY, P.H.; MOTTA, R.S. (Org.). Valorando a natureza: análise econômica para o desenvolvimento sustentável. Rio de Janeiro: Editora Campus, 1994. p.111-144.

FDZ-POLANCO, F. et al. Sustainability study for aerobic alternatives in municipal and industrial wastewater treatment. In: VII TALLER Y SIMPOSIO LATINO-AMERICANO-DIGESTION ANAEROBIA, Mérida, Yycatán, México, 2005.

FU-LIU, X.U. et al. A triangle model for evaluating the sustainability status and trends of economic development. Ecological Modelling, v. 195, n. 3-4, p. 327-337, 2006.

HOEPPNER, A.F.S. Comportamento de variáveis físicas, químicas e da eficiência de sistemas de lagoas de estabilização em ambiente tropical (Vale do Ribeira de lguape, SP). 286 f. Dissertação (Mestrado) - Escola de Engenharia de São Carlos da Universidade de São Paulo, São Carlos (SP), 2007.
IChemE. The sustainability metrics. Sustainable development working group of the institution of chemical engineers. 2001.

MIWA, A.C.P. Avaliação do sistema de tratamento de esgoto de Cajati, Vale do Ribeira de Iguape (SP), em diferentes épocas do ano. $212 \mathrm{f}$. Tese (Doutorado) - Escola de Engenharia de São Carlos da Universidade de São Paulo, São Carlos (SP), 2007

SAATY, T.L. How to make a decision: the analytic hierarchy process. European Journal of Operational Research, v. 48, p. 9-26, 1990

SACHS, I. Desenvolvimento sustentável, bioindustrialização descentralizada e novas configurações rural-urbanas. Os casos da Índia e do Brasil. In: VIEIRA, P.F.; WEBER, J. (Org.). Gestão de Recursos naturais renováveis e desenvolvimento: novos desafios para a pesquisa ambiental. São Paulo: Cortez, 1997. p. 469-494.

SÃO PAULO. Decreto n. 10755, de 22/11/77. Dispõe sobre o enquadramento dos corpos de água receptores na classificação prevista no Decreto 8468/76. São Paulo, 1977.

SILVA, A.B. Avaliação da produção de odor na estação de tratamento de esgoto Paranoá e seus problemas associados. 132 f. Tese (Mestrado) - Departamento de Engenharia Civil e Ambiental da Universidade de Brasília, Brasília, DF, 2007.

SISTEMA NACIONAL DE INFORMAÇÕES SOBRE SANEAMENTO (SNIS). Diagnóstico dos Serviços de Água e Esgoto, 2006. Brasília, DF: MCIDADES.SNSA, 2007.

SOARES, S.R.A.; BERNARDES, R.S.; CORDEIRO-NETTO, O.M Relationship between water supply, sanitation, public health, and environment: elements for the formulation of a sanitary infrastructure planning model. Cadernos de Saúde Pública, Rio de Janeiro, v. 18, n. 6, p. 1713-1724, 2002.

UNITED NATIONS ENVIRONMENTAL PROGRAM (UNEP). Recommendations for decision-making on basic sanitation and municipal wastewater services in Latin America and the Caribbean, 2003.

Von SPERLING, M. Introdução à qualidade das águas e ao tratamento de esgotos. $3^{\mathrm{a}}$ ed. Belo Horizonte: DESA/UFMG, 2005. 